DOI:http://dx.doi.org/105965/1982615x08162015037

\title{
A branquidade conservadora de Vogue Brasil no século XXI.
}

The Vogue Brazil's conservative whiteness in the XXI century

\author{
Daniela Novelli \\ Pós-doutoranda junto ao Centre de Recherches Interdisciplinaires sur les Mondes \\ Ibériques Contemporains (CRIMIC), da Université Sorbonne - Paris IV \\ danovelli@gmail.com
}

\section{Resumo}

A presente reflexão é parte integrante de recente pesquisa doutoral interdisciplinar sobre a produção imagética, narrativa e discursiva de uma branquidade conservadora nas páginas do periódico de alta moda e prêt-à-porter de luxo Vogue Brasil. Questões teórico-metodológicas inseridas notavelmente nos campos dos estudos culturais, de gênero e pós-coloniais são articuladas por meio de uma análise qualitativa de dois editoriais de moda, publicados nos anos de 2007 e 2008 e apontam para o "autoexotismo" da natureza e de nossa cultura popular - marcado simbolicamente pela primazia do corpo [branco] feminino, considerando-se ainda a legitimação de vozes produtoras de discursos de competência e renovação constante, bem como o cruzamento da violência simbólica racial com outras formas de dominação (de classe e de gênero/sexual).

Palavras-chave: autoexotismo; Vogue Brasil; branquidade.

\section{Abstract}

This reflection is part of recent interdisciplinary doctoral research about the imagery, narrative and discursive production of conservative whiteness in the high fashion journal pages and ready-to-wear luxury Vogue Brazil. Theoretical and methodological issues included notably in the fields of cultural studies, gender and postcolonial are articulated through a qualitative analysis of two fashion editorials, published in 2007 and 2008 and pointed to the "self-exoticism" of nature and Brazilian 


\section{ModaPalavra E-periódico}

popular culture - symbolically marked by the primacy of the body [white] women, considering also the legitimacy of producing voices speeches of competence and constant renewal, and the intersection of racial symbolic violence with other forms of domination (class and gender / sexual).

Keywords: self-exoticism; Vogue Brazil; whiteness.

\section{Introdução}

Inserida nos campos dos estudos culturais, de gênero e pós-coloniais, a análise da produção imagética e discursiva de uma branquidade conservadora em Vogue Brasil é parte de uma reflexão mais ampla" e aponta para o "autoexotismo" da natureza e de nossa cultura popular, simbolicamente marcado pela primazia do corpo [branco] ${ }^{2}$ feminino neste periódico de alta moda e prêt-à-porter de luxo ${ }^{3}$. A partir desta perspectiva, importantes questões teórico-metodológicas são abordadas por meio de uma análise qualitativa de dois editoriais de moda, publicados nos anos de 2007 e 2008.

Segundo Bouamama, Cormont e Fotia (2012), a brancura (co)produz habitus de maneira articulada e simultânea a outras formas de dominação de classe e de sexo/gênero, variáveis em diferentes contextos socioculturais e históricos. Se considerarmos a constituição discursiva "como estratégia do poder, como efeito de discurso", como bem colocou Villaça (2010, p. 15), veremos que a dimensão corporal e material da brancura está associada à dimensão simbólica e discursiva do poder racial [branco], funcionando como uma espécie de "vestimenta racial", muitas vezes não percebida enquanto racializada. Desta forma, a utilização do termo "branquidade" neste artigo (ao invés de branquitude) faz referência à tradução dos termos whiteness e blanchité no sentido dado por Horia Kebabza (2006), destacando não apenas aspectos positivos da cultura ou da identidade branca.

\footnotetext{
${ }^{1}$ NOVELLI, Daniela. A branquidade em Vogue (Paris e Brasil): imagens da violência simbólica no século XXI. Tese de doutorado. Universidade Federal de Santa Catarina, Florianópolis, SC, 2014. 345p.

2 O uso de colchetes no termo "branco" (incluindo sua aplicação no plural e/ou feminino) é adotado justamente para chamar a atenção para a invisibilidade social que o corpo branco da moda adquiriu no decorrer do processo de construção social e ocidental da branquidade, notavelmente no século XX.

${ }^{3}$ Referência ao segmento da "moda de luxo" vendida em Vogue, marcada pela invenção da Alta Costura [Haute Couture] na França e, mais recentemente, pela produção em série relativamente restrita de coleções sazonais. O Brasil, que não possui tradição em Alta Costura, está empenhado nos últimos anos em fabricar e exportar produtos dessas coleções de alta qualidade com maior valor agregado, de marcas que participam do São Paulo Fashion Week (SPFW) e Fashion Rio, incluindo setores de acessórios e perfumes.
} 


\title{
ModaPalavra E-periódico
}

A violência simbólica racial presente em Vogue Brasil por meio da branquidade abre espaço para entender outras formas de dominação, sendo instituída justamente porque a versão brasileira deste periódico dispõe apenas de instrumentos de conhecimento que ela possui em comum com a "matriz discursiva Condé Nast" (norteamericana e europeia) para pensar em sua própria relação com esta última - quando não pode então discordar da dominação estrangeira. Nesse sentido, o conceito de violência simbólica apontado por Pierre Bourdieu (1988, p. 41) torna-se bastante válido se considerarmos que a versão brasileira de Vogue é "apenas a forma incorporada da relação de dominação", aparentemente natural, uma vez que:

\begin{abstract}
A violência simbólica se institui por intermédio da adesão que o dominado não pode discordar do dominante (e então da dominação) quando ele dispõe, para pensá-lo ou se pensar ou, melhor, para pensar sua relação com ele, apenas de instrumentos de conhecimento que ele possui em comum com ele e que, sendo apenas a forma incorporada da relação de dominação, fazem aparecer essa relação como natural (BOURDIEU, 1998, p. 41).
\end{abstract}

O padrão corporal [branco] europeu exerce uma influência determinante na produção de capas e editoriais de Vogue Brasil na primeira década de nosso século, consagrando modelos brasileiras de projeção mundial, sendo muitas delas gaúchas e de descendência europeia. Brancas, jovens, sensuais e extremamente magras, elas ocupam um lugar central no imaginário [branco] da elite brasileira e personificam o corpo [branco] da moda e do luxo, contribuindo enormemente para determinada percepção estética corporal por parte das leitoras brasileiras de Vogue e pela socialização hierarquizada do gosto (Bordieu, 2007) junto às leitoras brasileiras.

Pode-se dizer ainda que a questão da violência simbólica observada nas páginas de Vogue sinaliza, antes de tudo, o papel das mulheres [brancas] numa economia de bens simbólicos, bem como o valor simbólico dessas mulheres disponíveis para troca. Paradoxalmente, as mulheres urbanas de poder aquisitivo médio a alto são as vítimas privilegiadas da dominação simbólica, mas também os instrumentos designados para retransmitir os efeitos na direção das categorias dominadas (Bourdieu, 1998).

A produção de uma branquidade conservadora no contexto brasileiro molda-se simbolicamente pela visão sublime e exótica de nossa natureza e pelo embranquecimento de figuras míticas femininas, como por exemplo: a prostituta de luxo das tardes (belle de jour) evocada no editorial "A Bela da Tarde", em 2004; a carioca urbana e "marrenta" que Gisele Bündchen incarna no editorial "Flagrada", em 2005 - mesmo ano em que ela representou a lavadeira da Bahia no editorial "Lata d'Água"; a personagem nordestina "Maria Bonita", que inspirou o editorial "O Sertão 


\section{ModaPalavra E-periódico}

está na Moda”, em 2006 ou ainda a rainha do carnaval personificada por Carol Trentini no editorial "Folia de Rainha", em 2008.

Assim, discursos e narrativas produzidos por Patricia Carta e seus colaboradores ${ }^{4}$ configuram páginas de um poder racial [branco], oscilando entre erotização e exotização do Outro e de si mesmo. É importante ressaltar que tanto o exotismo quanto o nacionalismo se referem a "posturas simplesmente relativas, uma vez que o objeto de interesse só se constrói comparativamente ao olhar daquele que observa e estabelece um julgamento de valor" (Murari, 1999, p. 47). Aliás, o olhar, como bem colocou Bourdieu (1998, p. 71), é um poder simbólico no qual a eficácia depende "da posição relativa deste que percebe e daquele que é percebido a partir do grau pelo qual esquemas de percepção e de apreciação operados são conhecidos e reconhecidos deste ao qual eles se aplicam".

Está presente em Vogue a questão da hegemonia histórica de "velhos centros" difusores da moda, notavelmente no que tange à eficácia simbólica de Paris no cenário internacional da alta moda e do prêt-à-porter, mesmo na era da globalização do luxo. Mas, se Patricia Carta e colaboradores de Vogue Brasil "autoexotizam” discursivamente nosso país, é porque a produção da branquidade se constrói pela celebração de uma Europa imaginada, baseada na apropriação e ressignificação de modelos estéticos e valores socioculturais (eurocêntricos) que por sua vez conduzem o olhar sobre os "modos de ver" o Brasil.

Embora estranhos e distantes, é como se estivéssemos unidos por "uma proximidade de matriz ocidental, língua neolatina e herança cultural europeia" (Leitão, 2007, p. 261). E as consequências paradoxais desta dominação simbólica podem ser notadas nas inúmeras vezes em que a moda brasileira "quer ser nacional" no processo de internacionalização, reinventando nossas tradições a partir de modelos culturais nos quais são identificadas continuidades com "determinado passado histórico", onde novos elementos são percebidos como existentes "desde sempre" (Hobsbawn, 2006).

Representações da natureza brasileira no contexto literário foram vistas por Roberto Ventura (1991) como associadas à ideia de "autoexotismo", ou seja, ligadas à identificação com o que haveria de original em nosso país, contrastando com o Velho Mundo - e principalmente no que dizia respeito à natureza tropical, fonte rica de

\footnotetext{
${ }^{4}$ A pesquisa abordou o período de 2001 a 2010, quando Vogue Brasil era publicada pela Carta Editorial.
} 


\section{ModaPalavra E-periódico}

imagens capazes de simbolizar nossa singularidade. Embora a expressão "autoexotismo" tenha sido empregada por Ventura no contexto da produção literária brasileira, torna-se bastante apropriada também para a produção imagética, textual e discursiva de um periódico (inter)nacional de alta moda, pois a concepção deste termo mostra-se válida para a interpretação de um processo histórico de exotismo pautado na identidade ou na originalidade do Brasil, bem como na exploração do tropical e do pitoresco no sentido europeu, por meio de representações da natureza e da cultura popular brasileira que combinam "o olhar voltado para aquilo que é estrangeiro e a percepção de si mesmo” (Murari, 1999, p. 47) nas páginas de Vogue.

Victor Segalen (1996) foi um dos primeiros teóricos a conceituar o exotismo, em seu inacabado Essai sur l'exotisme, como sendo essencialmente uma forma de reconhecimento da existência do Outro - considerando que este último não seria única e necessariamente o que estaria geograficamente distante. Estabelecendo uma tipologia de exotismos, apontou três tipos importantes: geográfico, temporal (ou histórico) e sexual. No primeiro deles, a distância do Outro é dada espacialmente e marcada frequentemente por diferenças étnicas e culturais (é o mais conhecido e comumente encontrado porque exotismo e conhecimento aprofundado da realidade diversa não coexistem para Segalen, sobretudo em sua vertente tropical); o segundo remete ao exotismo de um outro momento histórico idealizado, a partir do qual pode ocorrer a valorização de um passado idílico ou ainda de utopias aplicadas ao tempo futuro; no terceiro (menos abordado pelo pesquisador), a diferença entre o masculino e o feminino ocorre sem que haja um afastamento espacial ou temporal, ou seja, tem lugar em um mesmo lugar e em um mesmo tempo (Segalen, 1996).

É interessante notar que todos eles representam quase sempre algum tipo de idealização do Outro, supondo que ele pode ser em grande medida imaginado. Apesar de ser visto como uma positivação deste Outro devido principalmente à curiosidade e ao pouco ou quase nenhum conhecimento sobre ele, isso não impede que ocorra justamente o contrário, ou seja, sua negativação - aproximando exotismo de eurocentrismo. Concordo com Luciana Murari (1999, p. 47) quando defende a ideia de que podemos ver a própria expressão autoexotismo como "uma contradição em seus termos, à medida que combina o olhar voltado para aquilo que é estrangeiro e a percepção de si mesmo", mesmo porque os estereótipos muitas vezes "tomam a forma de inversão da autoimagem do espectador" (Burke, 2004, p. 157). 


\section{ModaPalavra E-periódico}

O que dizer do autoexotismo identificado na cultura brasileira por Ventura (1991) e perceptível também nas produções estéticas de Vogue Brasil, se o próprio exotismo é por natureza paradoxal? Representações exóticas do Novo Mundo, que opuseram frontalmente Europa e América nos séculos XVIII e XIX, estavam, segundo Murari (1999), associadas, por um lado, à ascensão de um sentimento nativista em relação aos valores físicos e naturais de uma América ainda "primitiva" e, por outro, ao poderoso referencial para a crítica da sociedade europeia.

\footnotetext{
À América foi lançada tanto a condenação por sua extrema juventude, ou imaturidade, quanto por sua antiguidade. A Europa, por sua vez, foi inúmeras vezes definida como um continente a caminho da decrepitude, devido à limitação territorial e ao virtual esgotamento de seus recursos naturais, enquanto ao Novo Mundo foi atribuído o sentido de futuro, de redenção e de vanguarda da humanidade (MURARI, 1999, p. 49).
}

Embora não seja objetivo deste artigo apresentar o processo de percepção e interpretação das imagens dos editoriais analisados como parte da já citada pesquisa doutoral em ciências humanas, é importante salientar o quanto este se fez extremamente dinâmico, no qual cada mensagem visual foi "desvendada" gradualmente com rigor para então cada editorial ser analisado em seu conjunto, facilitando assim a significação global das mensagens visuais no contexto brasileiro. Seguindo a metodologia de interpretação de imagens proposta por Martine Joly (1996), na qual a mensagem visual é constituída por três outras mensagens (plástica, icônica e linguística), foi possível identificar a construção imagética e discursiva de uma visão sublime do Brasil, a partir de uma vida natural, espontânea e harmoniosa em relação ao mundo.

\section{Editorial "Classe à beira-mar"}

O editorial de verão intitulado "Classe à beira-mar" foi publicado em $2007 \mathrm{e}$ trouxe a modelo brasileira Carol Trentini em trajes de banho, sendo fotografada pelo franco-brasileiro Jacques Dequeker. A modelo gaúcha, segundo Vogue, era na época "uma das tops brasileiras mais disputadas pelas grifes internacionais" (Falcão, 2007a, p. 97), mostrando que "sabe como poucas ser sensual sem perder a elegância", conforme escreveu a editora de moda Daniela Falcão (2007a, p. 97). Na mesma edição, Vogue anuncia que janeiro é "sinônimo de pouca roupa, pés no chão e cabeça fresca", convidando a leitora para "ficar o dia inteiro de biquíni, estirada na grama ou na areia, vendo o tempo passar sem nenhuma preocupação" (Falcão, 2007a, p. 97).

A América tropical de Vogue está longe de ser primitiva: é, antes de tudo, sofisticada, como sugerem o título do editorial e todo o restante da mensagem 


\section{ModaPalavra E-periódico}

linguística: "O passaporte para o verão está nos biquínis e maiôs com detalhes sofisticados, que resgatam o estilo clássico" (Falcão, 2007b, p. 98). Plasticamente, tonalidades de verde e amarelo, incluindo o dourado, contrastam com o preto e o branco dos biquínis e da iluminação, reforçando a ideia de luxo e elegância. A paisagem grandiosa, generosa e exuberante parece ser um importante significante plástico e icônico de uma "essência nacional" marcada por uma estética romântica que valoriza o passado nostálgico e perdido, onde "seria possível recuperar virtudes que faltam à realidade presente", conforme Murari (1999, p. 50).

Mas, diferentemente da atitude romântica que abandona o mundo burguês em favor da vida rural e do passado primitivo que tenha sido preservado de algum modo, a mulher [branca] deseja usufruir de todos os privilégios e benefícios de uma branquidade que lhe garante o tal "passaporte para o verão". A figura da nativa aparece "civilizada", cultivada à moda europeia, embora personificada pela potência juvenil e por toda a sensualidade naturalizada à brasileira que exala de Carol Trentini. Denise Sant'Anna (1995, p. 122) chama a atenção para a existência do "antigo sonho de ser moderno e civilizado", que há muito persegue as elites [brancas] do Brasil, sendo inclusive revelado pelo gesto que embeleza.

Talvez seja por isso que Carol tenha sido escolhida para este editorial, revelando a parte traseira do seu corpo com discrição e sofisticação ao usar um modelo de biquíni imaginado pelo olhar estrangeiro (de dimensões maiores do que as geralmente usadas pela maioria das mulheres brasileiras), evocando assim a "maneira brasileira" de ser branca e rica. Maneira que inclui traços de um autoexotismo construído por nuances de erotização do corpo, que se torna ele próprio objeto do desejo colonial [branco] na medida em que sua imagem paradoxal remete em alguns momentos à figura da índia nativa (embranquecida) - disponível sexualmente, com cabelos desalinhados e selvagens e com expressões faciais e corporais que convidam ao prazer do voyeur e, em outros, à figura de uma mulher [branca] bela, magra e jovem, quase inacessível.

\section{Editorial "Folia de Rainha"}

O editorial intitulado "Folia de Rainha" é um bom exemplo para explicar porque a produção de uma branquidade conservadora em Vogue deve ser percebida dentro de um quadro sociocultural mais amplo, fruto de um complexo processo histórico de colonização, marcado pela influência européia neoclássica e interrogado mais tarde pelos modernistas da vanguarda artística dos anos 1920. Entretanto, o projeto brasileiro 


\section{ModaPalavra E-periódico}

de modernização foi sustentado pela elite [branca] dirigente, composta em sua maioria de intelectuais nacionalistas - e, portanto, um olhar carregado de autoexotismo sobre a cultura popular e a natureza de nosso país pareceu coexistir às novas propostas estéticas de caráter mais social, com temas regionalizados.

A modelo Carol Trentini, desta vez fotografada por Gui Paganini, "encarna uma passista de escola de samba com queda pelo street, mesclando plumas com boné, paetês com regatas e jeans com muito brilho" (Falcão, 2008, p. 96). Além do vestido de plumas, Trentini usa maiôs (de malha dupla-face e de paetê), jaqueta (jeans com brilho), jardineira (jeans), camiseta e regata estampadas, bermuda (de plumas), além de pingentes, acessórios de cabeça criados por Walério Araújo e um adereço carnavalesco antigo da Escola Beija-Flor.

Palavras estrangeiras, recorrentes em Vogue, funcionam iconicamente como "passaporte para uma sociedade moderna, aqui representada pelo mundo do entretenimento" (Garcia, 2004, p. 94): street [rua], dress code [código do vestir] e glam [abreviação de glamour] legitimam discursivamente o elevado capital cultural associado às leitoras de Vogue e revelam ao mesmo tempo um ethos constituído pela globalização “americana" apontada por Stuart Hall (2013). Desta forma, Vogue Brasil participa de um movimento de interdependência simbólica para naturalizar o capital cultural

adquirido por suas leitoras, que as permite justamente apreender os sentidos atribuídos aos termos linguísticos empregados nos editoriais de moda, tais como "ser maravilhosa sem fazer força" ou "sem compromisso com o dress code".

A composição visual das peças citadas contribui para a reprodução do efeito hilo, um recurso estilístico, conceitual e comportamental utilizado no campo da moda na década de 2000, percebido notavelmente pela fusão do estilo glamouroso (clássico, deslumbrante, sofisticado) com o estilo casual (esportivo, jovem, descontraído). Iconicamente, o hi-lo (abreviatura de high-low [alto-baixo]), significa mistura "do caro com o barato", "do chique com o brega", "do nobre com o simples". E por que não "da elite com o povo"? A "passista" de Vogue usa sandálias e patins; simples regatas não são tão simples assim (Balenciaga); peças de $\mathrm{R} \$ 28,00$ e $\mathrm{R} \$ 11.160,00$ fazem parte do mesmo visual [look]; o industrial vira artesanal; maiôs são usados com jaquetas, plumas com bonés e jeans com muito brilho.

Tomado como fonte de inspiração, o "popular" acaba permanecendo dentro dos padrões de gosto das classes médias e altas porque é exotizado (Leitão, 2007, p. 317). Pode-se dizer que "Folia de Rainha" revela a produção discursiva de uma branquidade 


\section{ModaPalavra E-periódico}

que se apropria de referências estéticas da cultura popular - como é o caso do carnaval e do universo da rua [street] - para mesclar determinados significantes (étnicos/raciais, de gênero/sexuais e de classe) de forma que eles conotem uma espécie de "harmonia de contrastes", representando esteticamente uma identidade nacional (brasileira) democrática e multicultural.

Segundo Peter Fry (1982), quando símbolos de "fronteiras" étnicas são convertidos em símbolos que afirmam os limites da nacionalidade, converte-se também o que era originalmente perigoso em algo "limpo, seguro e domesticado". Se, por um lado, o fundo branco escolhido pode estar remetendo à ideia de neutralidade (recorrente no universo da moda contemporânea apresentada em Vogue), por outro pode estar representando justamente a vontade de "limpeza, domesticação e segurança" apontada por Fry, simbolizando assim a dominação racial [branca]. Carol Trentini é jovem, alta, magra, loira e de olhos claros, possui uma "forma extrema de brancura" (Dennison, 2013, p. 294) que se torna um poderoso significante de determinados valores simbólicos da brancura - luz, virtude, pureza, excepcionalidade, transcendência, beleza, civilização, autocontrole, apontados por Dennison (2013) em relação à figura de Xuxa no Brasil.

O acessório de bananas na cabeça de Trentini é um poderoso significante plástico e icônico que remete aos arranjos de frutas que a mítica baiana estilizada por Carmen Miranda costumava usar nas décadas de 1940 e 1950, quando mostrou seu traje ao Cassino da Urca e aos Estados Unidos, por meio do cinema nacional. Os laços identitários de Carmen não eram com a tradição baiana, mas "com a cidade espetáculo, com o mundo do entretenimento" (Garcia, 2004, p. 111), ou seja, trata-se de um bom exemplo de como a reinvenção da indumentária da cantora foi construída no diálogo entre o local e o global - menos regional e mais cosmopolita.

Assim, determinados signos associados cultural e historicamente à elite [branca] são estrategicamente manipulados por diretores, produtores, editores e fotógrafos para exotizar a cultura popular brasileira em prol de um nacionalismo racista e conservador, mantido pelo interesse político dos que estão "interessados no exótico das festas", como aponta Garcia (2004, p. 122). E ainda, a construção simbólica da figura da passista em Vogue Brasil enfatizou ou omitiu certos aspectos típicos de trajes (do carnaval brasileiro) para acrescentar outros, a partir de referências estrangeiras.

Percebe-se, portanto, uma espécie de aproximação simbólica dos produtores de discurso em Vogue com o universo afro-brasileiro, mas que entretanto é negado por uma branquidade que legitima diferenças sociais ao se apropriar simbolicamente desta 


\section{ModaPalavra E-periódico}

figura, embranquecendo-a e erotizando-a. Neste editorial, a figura da mulata do carnaval é um significante (in)visível, uma vez que ela é negada e evocada ao mesmo tempo. Algumas posturas corporais mais rígidas e angulosas convivem com uma nudez estrategicamente revelada e parecem desconstruir a sensualidade associada culturalmente à mulata, porque vindas do universo do esporte.

Como mulher-corpo, mulher-sedução, a mulata "se engaja em um tipo de mediação/comunicação bastante distante do modelo de mulher que viabiliza, como signo, através do casamento e das identidades de esposa e mãe, a aliança entre duas famílias" (Giacomini, 1994, p. 220), cujo valor advém exclusivamente da sexualidade. Isso significa que imaginários culturais populares entram em cena, sendo ressignificados a partir de apropriações simbólicas de determinado status racial e pelas condições sociais, políticas e econômicas associadas à própria produção discursiva de uma branquidade conservadora que é fruto de um (in)visível privilégio racial.

Corroborando com Leitão (2007, p. 316), a apropriação de elementos populares parece ser mais um "jogo possível a partir do completo domínio dos códigos de (bom) gosto do que propriamente abertura ou recusa de tais códigos". Ambiguamente atraídos e repelidos por nossa elite [branca], tais códigos acabam reforçando o exotismo da cultura popular brasileira.

[...] em todos os campos, a estilização da vida, ou seja, o primado conferido à forma em relação à função, à maneira em relação à matéria, produz os mesmos efeitos. E nada determina mais a classe e é mais distintivo, mais distinto, que a capacidade de constituir, esteticamente, objetos quaisquer ou, até mesmo, 'vulgares' (por serem apropriados, sobretudo, para fins estéticos, pelo 'vulgar') ou a aptidão para aplicar os princípios de uma estética 'pura' nas escolhas mais comuns da existência comum - por exemplo, em matéria de cardápio, vestuário ou decoração da casa - por uma completa inversão da disposição popular que anexa a estética à ética (BOURDIEU, 2007, p. 13).

Se a "autoexotização" da natureza e da cultura popular brasileira em Vogue Brasil mostra o quanto nosso país foi e ainda é o exótico do europeu, mostra também que o "povo" é o exótico da elite fashion brasileira, como bem definiu Leitão (2007, p. 320). Na realidade, a grande maioria das edições brasileiras analisadas na pesquisa doutoral sobre Vogue abordava a ressignificação de uma iconografia ligada ao passado colonial, submetendo a um branqueamento estratégico determinadas representações simbólicas de mulheres mestiças que haviam se tornado emblemáticas no imaginário coletivo construído em relação ao Brasil ao longo dos últimos séculos, algumas delas citadas no início desta reflexão. 


\section{ModaPalavra E-periódico}

Ao longo dos anos 2000, nota-se o embranquecimento das "rainhas de baterias" de muitas escolas de samba do Rio de Janeiro, marcando a substituição das tradicionais mulatas (provenientes das próprias comunidades que representavam) por mulheres brancas (consideradas musas do carnaval), em sua maioria atrizes e artistas da televisão brasileira, como Grazi Massafera e Adriane Galisteu, que desfilaram em 2007 e 2008, respectivamente, para as escolas de samba Grande Rio e Unidos da Tijuca.

\section{Considerações finais}

A raça mostra-se uma importante construção discursiva que organiza a diferença, ao mesmo tempo em que é um "significante flutuante" (Hall, 2013). O corpo [branco] feminino de Vogue, embora atravessado por distintos aspectos socioculturais em contextos europeus e latinos, tornou-se "invisível” por ser justamente um corpo dominante discursivamente e naturalizado pelo ethos de uma branquidade conservadora no campo da alta moda e do prêt-à-porter de luxo, trazido inclusive por este periódico ao longo de sua história.

Vogue Brasil reafirmou que o branqueamento é um importante aspecto da branquidade no contexto brasileiro (Bento, 2002) e a violência simbólica instituída pela matriz norte-americana e europeia no Brasil é exemplar de como a versão brasileira de Vogue dispõe apenas de instrumentos fornecidos pelo conhecimento comum que é gerado para pensar sobre sua relação com ela, uma vez que não pode discordar do poder [branco] simbólico estrangeiro.

Nesse sentido, a produção discursiva de Vogue Brasil é natural apenas aparentemente, explicando assim a "autoexotização" da natureza e da cultura popular brasileira e a erotização do corpo [branco] feminino. Nos editoriais analisados de Vogue, este marcador está intimamente associado ao nacionalismo e à erotização do corpo [negado e evocado] da mulata brasileira. Finalmente, raça, corpo e nação encontram-se inter-relacionados em tais representações, levando-nos a refletir sobre algumas configurações discursivas relacionadas ao uso do corpo da mulher [branca] para favorecer o privilégio racial branco na mídia contemporânea (inter)nacional, em sintonia com o antigo projeto nacionalista e modernizador da elite [branca] dirigente de nosso país.

\section{Referências}




\section{ModaPalavra E-periódico}

BENTO, Maria Aparecida Silva. Branqueamento e branquitude no Brasil. In: BENTO, M. A. S.; CARONE, Iray (Orgs.). Psicologia social do racismo: estudos sobre branquitude e branqueamento no Brasil. Petrópolis, RJ: Vozes, 2002. p. 25-57. BOUAMAMA, Saïd; CORMONT, Jessy; FOTIA, Yvon (Dir.). Dictionnaire des dominations de sexe, de race, de classe. Collectif Manouchian. Paris : Éditions Syllepse, 2012.

BOURDIEU, Pierre. Questions de sociologie. Paris : Minuit, 1988. La domination masculine. Paris : Le Seuil, 1998. A distinção: crítica social do julgamento. Tradução de Daniela Kern;

Guilherme J. F. Teixeira. São Paulo: Edusp; Porto Alegre: Zouk, 2007.

BURKE, Peter. Testemunha ocular. Bauru: EDUSC, 2004.

DENNISON, Stephanie. Blonde Bombshell: Xuxa and Notions of Whiteness in Brazil. Journal of Latin American Cultural Studies, 2013, Travesia, 22:3, 287-304, . Disponível em: <http://dx.doi.org/10.1080/13569325.2013.804810>. Acesso em 22/01/2014.

FALCÃO, Daniela. Ponto de vista. Vogue Brasil. São Paulo, Carta Editorial, n. 341, $2007 \mathrm{a}$.

Classe à beira-mar. Vogue Brasil. São Paulo, Carta Editorial, n. 341, 2007 b. Ponto de vista. Vogue Brasil. São Paulo, Carta Editorial, n. 354, 2008.

FRY, Peter. Para inglês ver. Rio de Janeiro: Zahar, 1982.

GARCIA, Tânia da Costa. $O$ "it verde e amarelo" de Carmen Miranda (1930-1946). São Paulo: Annablume; Fapesp, 2004.

GIACOMINI, Sonia Maria. Beleza mulata e beleza negra. Estudos Feministas. Florianópolis, ano 2, 2o semestre/1994.

HALL, Stuart. Identités et cultures 2. Politiques des différences. Paris: Éditions Amsterdam, 2013.

HOBSBAWN, Eric. Introdução: a invenção das tradições. In: HOBSBAWN, Eric; RANGER, Terence. A invenção das tradições. São Paulo: Paz e Terra, 2006. 


\section{ModaPalavra E-periódico}

JOLY, Martine. Introdução à análise da imagem. Campinas: Papirus, 1996.

KEBABZA, Horia. « «L'universel lave-t-il plus blanc ? » : « Race », racisme et système de privilèges », Les cahiers du CEDREF [En ligne], 14 | 2006. Disponível em: <http://cedref.revues.org.gate3.inist.fr/428>. Acesso em 13/10/2013.

LEITÃO, Débora Krischke. Brasil à moda da casa: imagens da nação na moda brasileira contemporânea. Tese de Doutorado (Programa de Pós-Graduação em Antropologia Social) - Instituto de Filosofia e Ciências Humanas - Universidade Federal do Rio Grande do Sul: Porto Alegre, 2007. 373 p.

MURARI, Luciana. O culto da diferença: imagens do Brasil entre exotismo e nacionalismo. Revista de História, 141 (1999), 45-58.

SANT'ANNA, Denise Bernuzzi de. Cuidados de si e embelezamento feminino: fragmentos para uma história do corpo no Brasil. In: SANT'ANNA, Denise B. de (Org.). Políticas do corpo. São Paulo: Estação Liberdade, 1995. p. 121-139.

SEGALEN, Victor. Essai sur l'exotisme. Paris: LGF, 1996.

VENTURA, Roberto. Estilo tropical: história cultural e polêmicas literárias no Brasil. São Paulo: Companhia das Letras, 1991.

VILLAÇA, Nízia. Mixologias: comunicação e o consumo da cultura. SP: Estação das Letras e Cores, 2010.

VOGUE BRASIL. São Paulo, Carta Editorial, n. 341, 2007. São Paulo, Carta Editorial, n. 354, 2008. 